\title{
Fuzzy Logic Controlled Renewable Energy based DC Smart-Grid-System with Improved-Performance
}

\author{
K. Selvakumar, S. Pandiammal, K.Saravanan
}

\begin{abstract}
The DC smart-grid-system (DCSGS) becomes more and more popular and it is seen as an alternative to the AC. In DCSGS, voltage quality and harmonic distortion issues affects the performance of integrated renewable power sources. To improve the voltage quality, SEPIC converter is used to step up the output of PV cell. In DCSGS, output of PV is stepped-up using SEPIC. The output of wind generator is also rectified and stepped-up using SEPIC. This effort covenants with modeling\&-simulation of CL(closed-loop)-DC-SGS (smart grid system) with PR controller and FLC in DCSGS. The performance of DCSGS with $P R$ and FLC are compared and their results are presented. The results indicate that FLC controlled close-loop DCSGS gives superior response.
\end{abstract}

Keywords- Smart-Grid (SG), Renewable-energy-resources, Energy-storage-systems, Integration, Power-electronics, SEPIC, Photovoltaic-model, wind VSC, PR-proportional-resonant, FLC-Fuzzy logic controller

\section{INTRODUCTION}

These days, the wide dissemination of conveyed RES introduces another situation intended for the guideline of allocation-frameworks \& the accessibility of novel advances for capacity frameworks energizes their utilization in power frameworks [1]. The-utilization of a PMS is vital to upgrade the power-course through the diverse segments of the MG\& the trading of power with the electric-network. SGS allude to the utilization of controls innovation and computerized data to build the security, unwavering quality and productivity of the electric matrix on the planet [2].

The SGS is perhaps incorporated from different sustainable power sources [3], for example, wind turbine [4, $5,6]$, energy component [7, 8], \&PV [9, 10, 11]. One of the different sustainable power sources that can possibly be used is PV [12]. The conveyance of power from PV frameworks is conceivable independent or grid-associated. For lattice applications, PV frameworks went through the three-stage inverter and this condition requests high DC voltage [13]. Be that as it may, qualities of photovoltaic create low voltage and don't meet this necessity. The step-up converter is required to beat this issue by changing over low DC voltage from PV to high DC voltage [14].

For the most part, the favored topology of the

Revised Version Manuscript Received on 10, September 2019.

K. Selvakumar, Department of EEE, SRM University, Chennai, Tamilnadu, India - 603203 (Email: selvakse@ gmail.com)

S. Pandiammal, Department of EEE, SRM University, Chennai, Tamilnadu, India - 603203 (Email: pandiammalsendrayal@gmail.com)

K.Saravanan Department of EEE, SRM University, Chennai, Tamilnadu, India - 603203 (Email: saravanank96@gmail.com) step-up-converter can produce high advance up voltage, high proficiency, and low swell of the yield/input voltage \&current [15]. Numerous analysts have created and examined the execution of the step-up converter for PV frameworks. Boost-converter [16- 19] can produce high advance up voltage with high duty-cycle. That condition may cause voltage weight on the switching gadget and diminishing the proficiency of the Boost-converter.

The high advance up voltage can likewise be gotten from two Boost converters that are masterminded in series with a solitary switch; it is called Quadratic-Boost-Converter [20, 21]. In any case, switching gadget gets high current pressure. Then again, conduction misfortunes likewise increment, and the productivity of this converter diminishes [22].

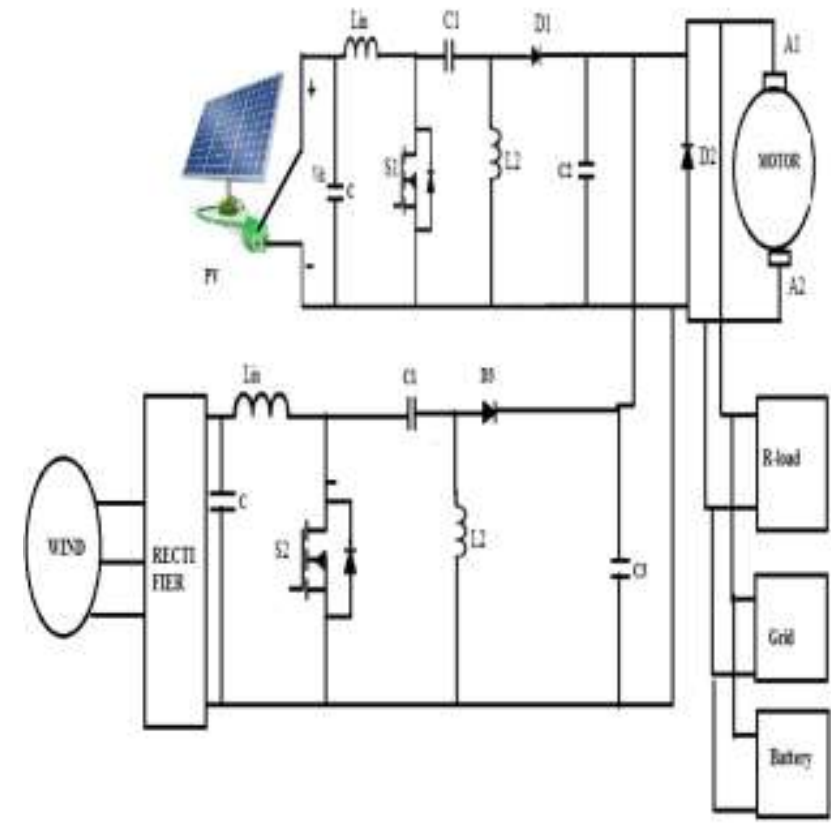

Figure 1. Circuit-diagram of -DC smart grid system

\section{PROPOSED DESIGN AND ANALYSIS}

The exceeding literature does not deal with comparison of closed loop -DC smart grid system with PR controller and FLC in PV based SGS. Hence, the present effort deals with comparison of closed loop DC smart grid system with PR controller and FLC in hybrid based DCSGS. This work proposes PR for the control of DCSGS. 
$L=L_{I^{-}} L_{D^{-}} L_{s h}$

The current-diverted through the-diode is given by Equation (2).

$$
\begin{aligned}
& L_{D}=L_{0}\left[\exp \left(\frac{q\left(V+L R_{S}\right)}{n k T}\right)-\right. \\
& \cdots \ldots \ldots \ldots \ldots \ldots \ldots \ldots \ldots \ldots \ldots \ldots \ldots \ldots \ldots \ldots \ldots \\
& L=L_{I}-L_{0}\left[\exp \left(\frac{q\left(V+L R_{S}\right)}{n k T}\right)-1\right]-
\end{aligned}
$$$$
1] \text {. }
$$

Consequently, the phrase of (3), abridge to as Equation (4).

$$
L=L_{I}-L_{0}\left[\exp \left(\frac{q\left(V+L R_{S}\right)}{n k T}\right)-\right.
$$

$1]$.

A '-PV-board' is generated of numerous sun based-components", -which-are associated in-sequence or -analogous with the yield-current\&-voltage of the-PV-panel.

Output of PV is DC Smart Grid System. The pulses required by fly-back converter are generated by a PIC and they are amplified by using a driver. The Block diagram of Existing and proposed is appeared here. The closed loop SEPIC converter with PR and FL controller are delineted in Fig 3,4.

Figure 1. Circuit-diagram of -DC smart grid system

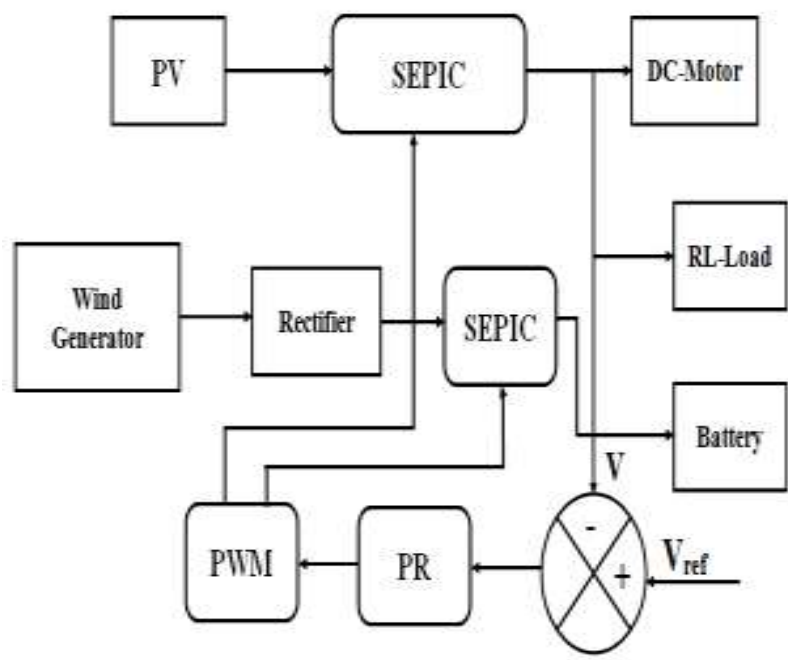

Figure 2. Block-diagram of closed-loop SEPIC-converter with PR-controller

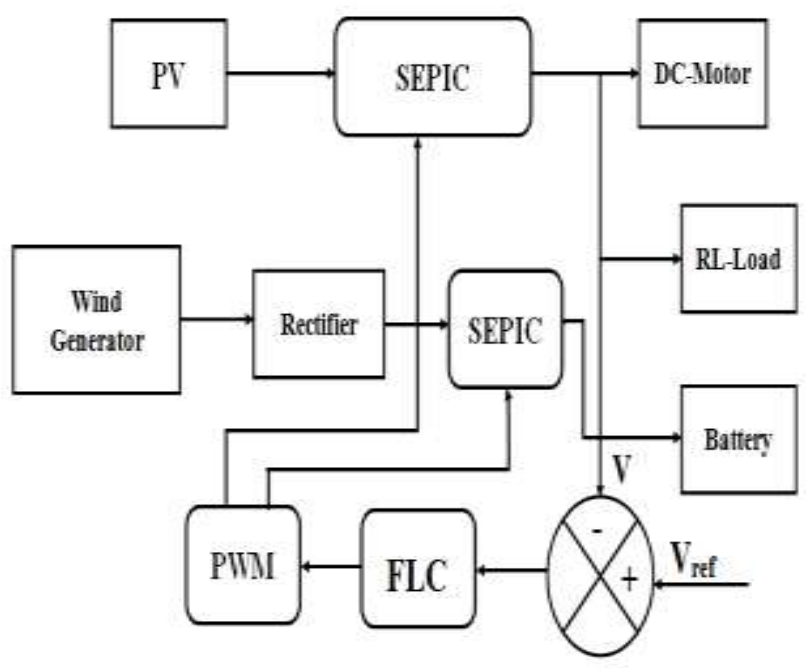

Figure 3. Block-diagram of closed-loop SEPIC-converter with FLC Controller

\section{FUZZY LOGIC CONTROLLER}

Fuzzy controller is an adaptable control technique that provides the ability to operate in load variations, supply variations and other disturbances for the proposed SEPIC converter. This controller affords consistence performance and maintains stability. The principle points of interest of a framework with FLC are high adaptability, strength, unwavering quality, execution adaptability and great powerful reaction.

The benefits of FLC over usual-controllers-like PR-controllers are that they don't require precise arithmetical-model, they can operate with indefinite-inputs, can switch-non-linearity, load-annoyances \&so-on.

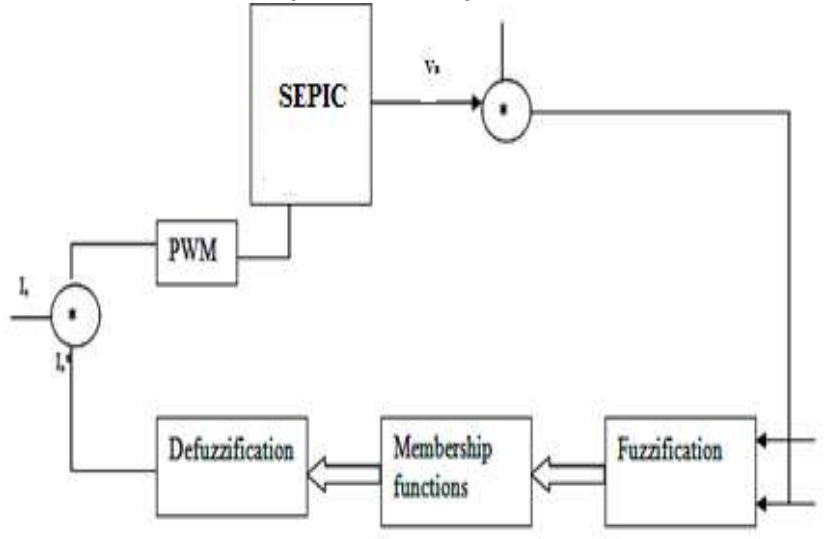

Figure 4. Block--diagram of FLC

Figure 5. delineates the block-diagram of the implemented-FLC-scheme of a SEPIC. Consecutively to execute the CA(control-algorithm) of a sepic PR and FLC in closed-loop, the DC-side-capacitor-voltage is logical \& evaluated with a reference-value.

\section{RESULTS AND DISCUSSION}

Closed loop - DC smart grid system with PR controller in PV based SGS is delineated in Figure 6. First when the $\mathrm{PV}$-system is on the voltage is stored in the capacitor. Then, the yield of the PV-system is fed to closed-loop-DC-SGS with PR-controller where the voltage may be stepped-up to uphold the constant-voltage at the-yield. 


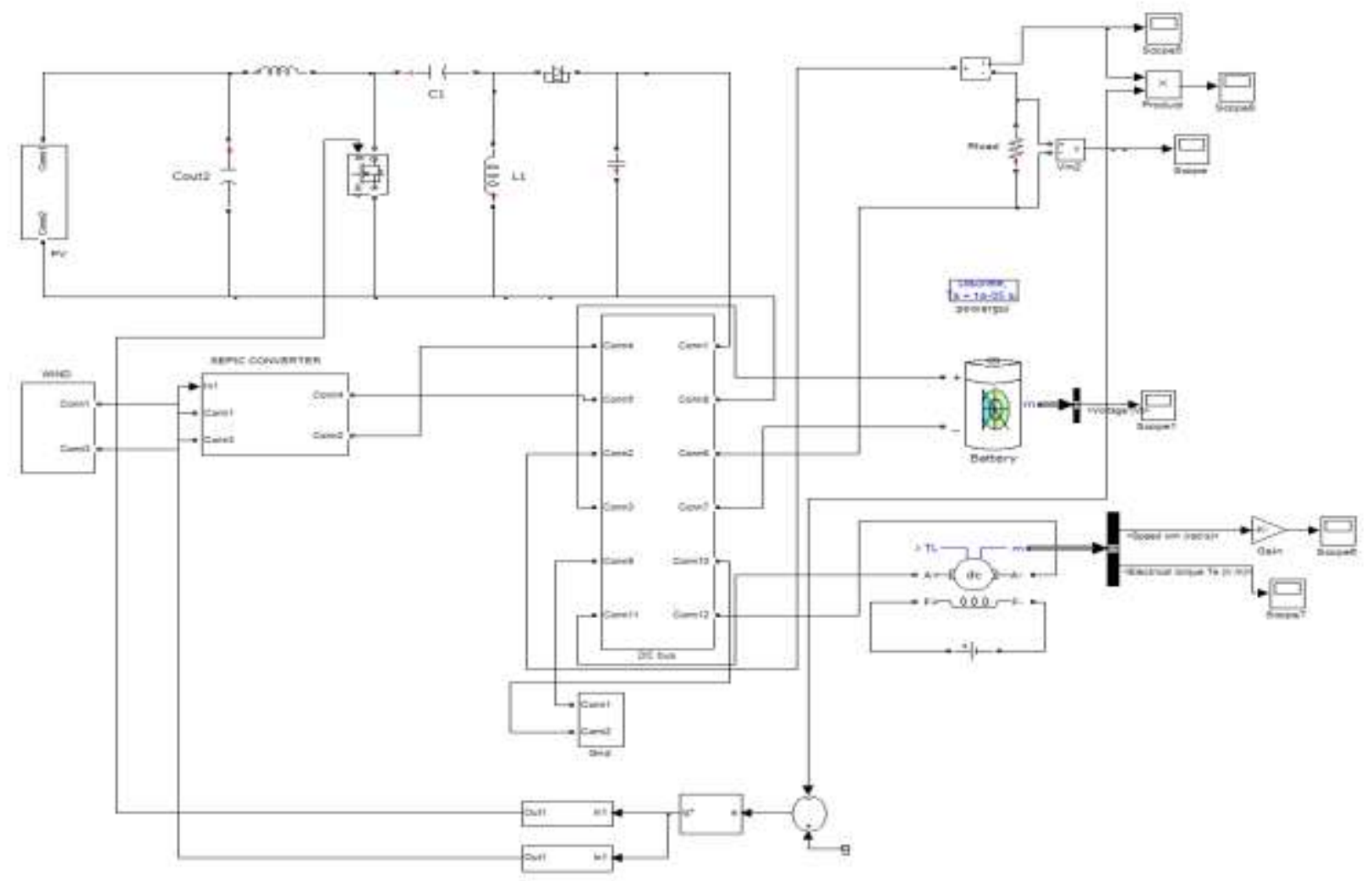

Figure 5. Circuit-diagram of SEPIC-converter with-PR controller

The yield of the PV-system is $18 \mathrm{~V}$. Under partial-shading , the voltage is increased from $10 \mathrm{~V}$ to $18 \mathrm{~V}$. This is the input voltage closed loop DC-SGS with PRcontroller which is appeared in Figure 6. The diminution in-voltage is due to the partial shading.

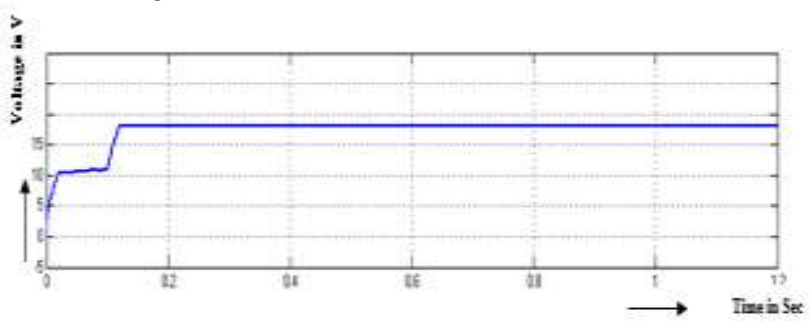

Figure 6. Input voltage of CLSGS SC with PR

The output Voltage of closed loop DC smart grid system with PR controller in SGS is delineated in Figure7 \&its peak-value is $99 \mathrm{~V}$. Thus the yield-voltage of inverter is regulated by using PR controller.

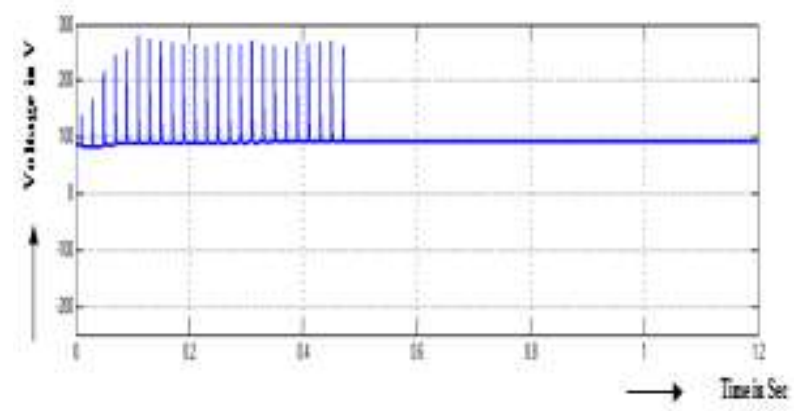

Figure 7. Output voltage of CLSGS SC with PR

The output current of closed loop DC-SGS with
PR-controller is delineated in Figure8. This is approximately 1A. The yield-current of inverter increases \&then reaches normal value. Thus the yield-current of inverter is regulated by utilizing PR controller.

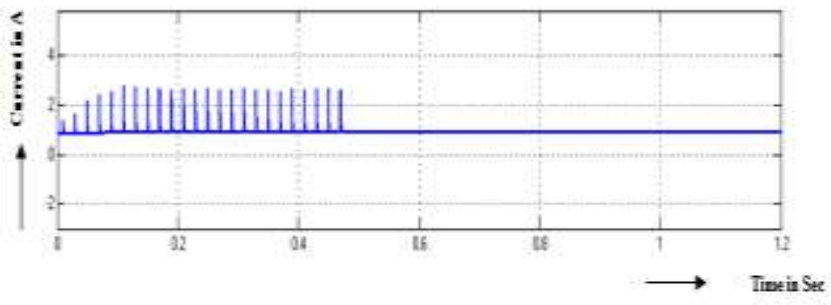

Figure 8. Output current of CLSGS SC with PR

Motor speed of closed loop DC smart grid system with PR controller in SGS is delineated in Figure 9 \&its increased-value is $750 \mathrm{RPM}$.

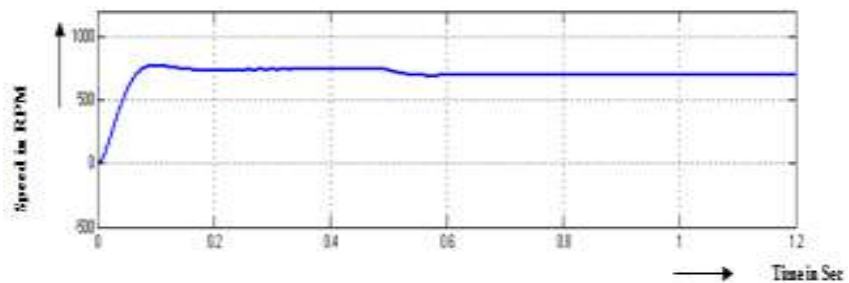

Figure 9. Motor speed of CLSGS SC with PR 


\section{FUZZY LOGIC CONTROLLED RENEWABLE ENERGY BASED DC SMART-GRID-SYSTEM WITH IMPROVED-PERFORMANCE}

Motor torque response of closed loop DC-SGS with PR controller is delineated in Figure 10 and its value is decreases from $80 \mathrm{~N}-\mathrm{m}$ to $1.5 \mathrm{~N}-\mathrm{m}$.

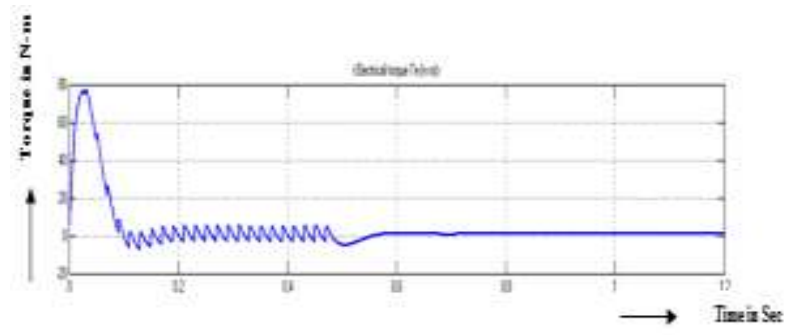

Closed-loop-Smart-grid system with Fuzzy Logic-controller in SGS is appeared in Figure 11. First when the PV system is on, the voltage is stored in the capacitor.Then, the yield of the PV-system is fed to the SGS sepic-converter with Fuzzy Logic-controller where the voltage may be stepped up to maintain the constant voltage at the output.

Figure 10. Motor Torque of CLSGS SC with PR
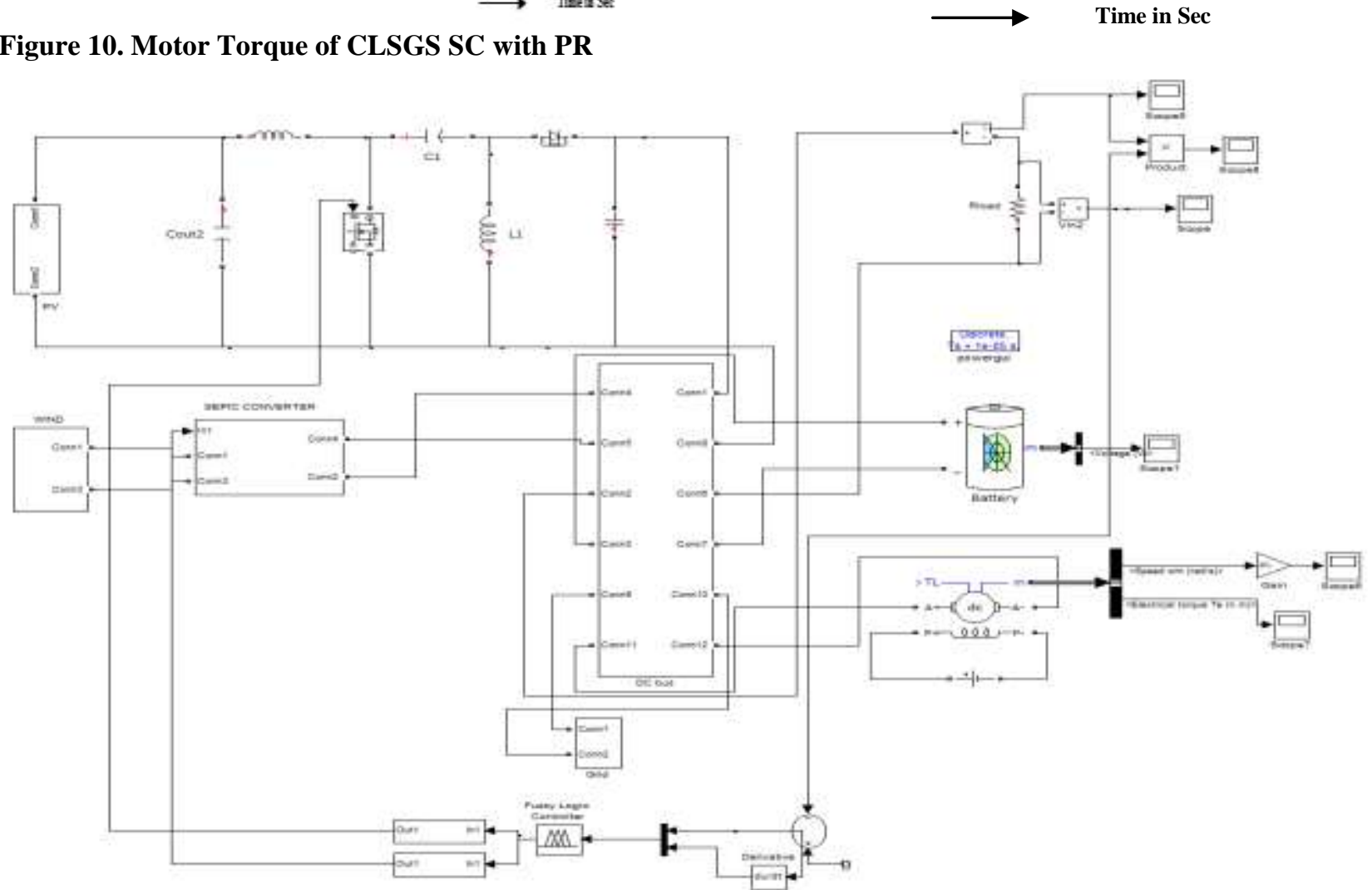

Figure 11. Circuit diagram of closed loop SEPIC converter with FL controller

Input voltage of CLSGS SC with FLC is appeared in Figure 12 and its value increase from $11 \mathrm{~V}$ to $18.5 \mathrm{~V}$.

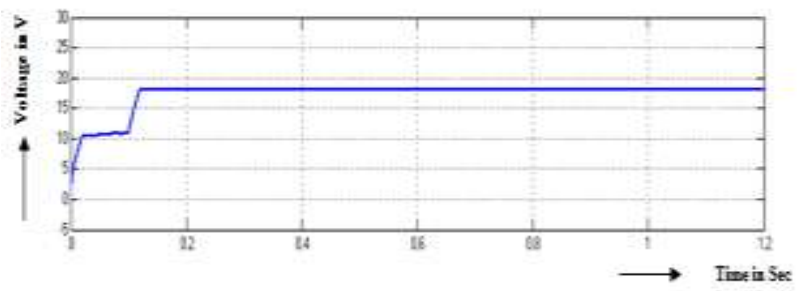

Figure 12. Input voltage of CLSGS SC with FLC

The output voltage of CLSGS SC with FLC is shown in Figure 13 and it is approximately $88 \mathrm{~V}$. The output voltage of CLSGS SC with FLC is regulated by using FL controller.

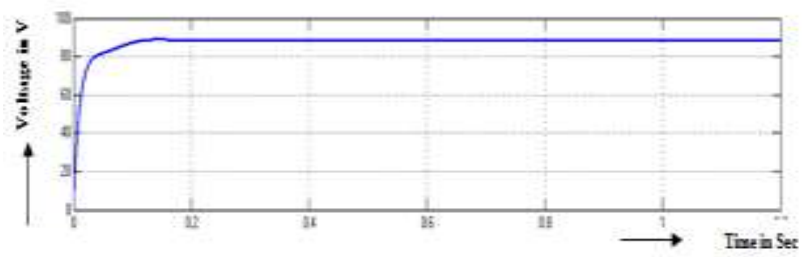

Figure 13. Output voltage of CLSGS SC with FLC
The output current of CLSGS SC with FLC is shown in Figure14. This is approximately 0.9A. Thus the yield-current of-inverter is regulated by using FL-controller.

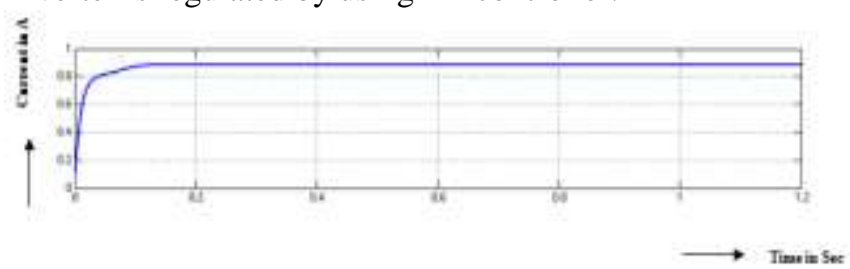

Figure 14. Output current of CLSGS SC

The motor-speed is outlined in Figure15 \&its-value-is 700RPM.

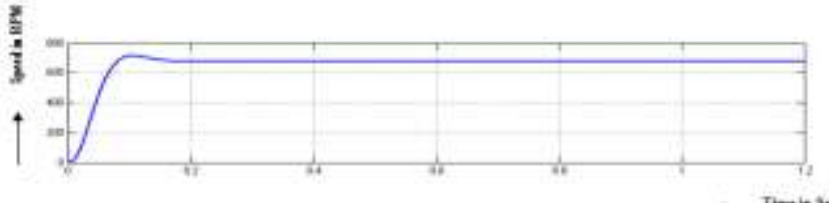

Figure 15. Motor-speed of CLSGS SC 
MT (Motor Torque) of CLSGS SC with-FLC is- outlined in Figure 16 \&its-value-is $0.89 \mathrm{~N}-\mathrm{m}$.

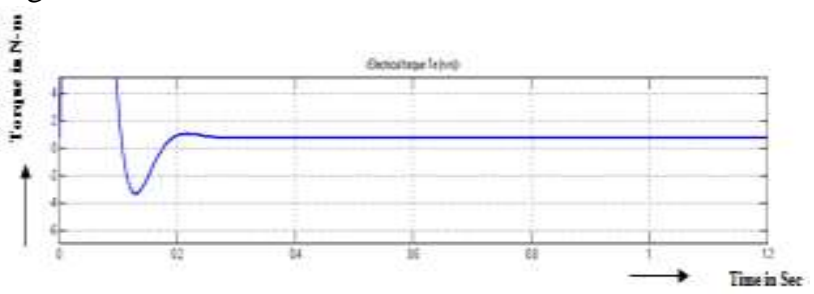

Figure16. Motor-Torque of CLSGS SC with FLC

The-evaluation of TDP (time domain parameters) with PR \&FLC is specified in Table-1. By utilizing FLC, the 'RT (rise time)' is lessened from $0.09 \mathrm{Sec}$ to $0.07 \mathrm{Sec}$; the 'PT (peak time)' is lessened from 0.32 to $0.09 \mathrm{Sec}$; the 'ST (Settling time)' is lessened from 0.50 to $0.20 \mathrm{Sec}$ and 'SSE (steady state error)' is lessened from 2.8 to 0.7 Volts.

Table -1 Comparsion of-time domaion-parameters with PR and FLC

\begin{tabular}{|l|l|l|l|l|}
\hline Controller & $\mathrm{T}_{\mathrm{r}(\mathrm{Sec})}$ & $\mathrm{T}_{\mathrm{s}(\mathrm{Sec})}$ & $\mathrm{T}_{\mathrm{p}(\mathrm{Sec})}$ & $\begin{array}{l}\mathrm{E}_{\mathrm{ss}} \\
\mathrm{r}(\mathrm{Volts})\end{array}$ \\
\hline PR & 0.09 & 0.50 & 0.32 & 2.8 \\
\hline FLC & 0.07 & 0.20 & 0.09 & 0.7 \\
\hline
\end{tabular}

Hardware snap shot SGS sepic converter is delineted in Figure 17.

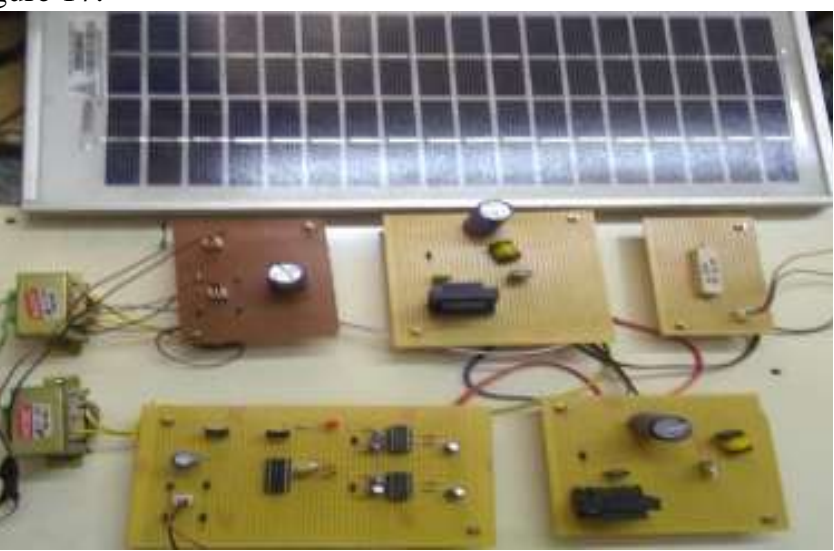

Figure 17 Hardware snap shot sepic converter

Input voltage is appeared in Figure 18.

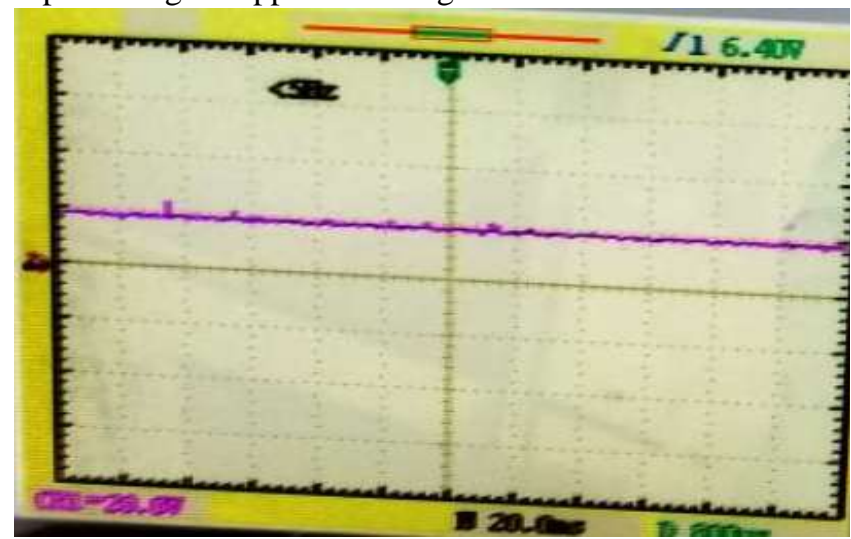

Figure 18 Input voltage

Switching pulse for SEPIC converter S1 is appeared in Figure 19. The Switching pulse for SEPIC converter S2 is shown in Figure 20. The Output voltage is presented in Figure 21.

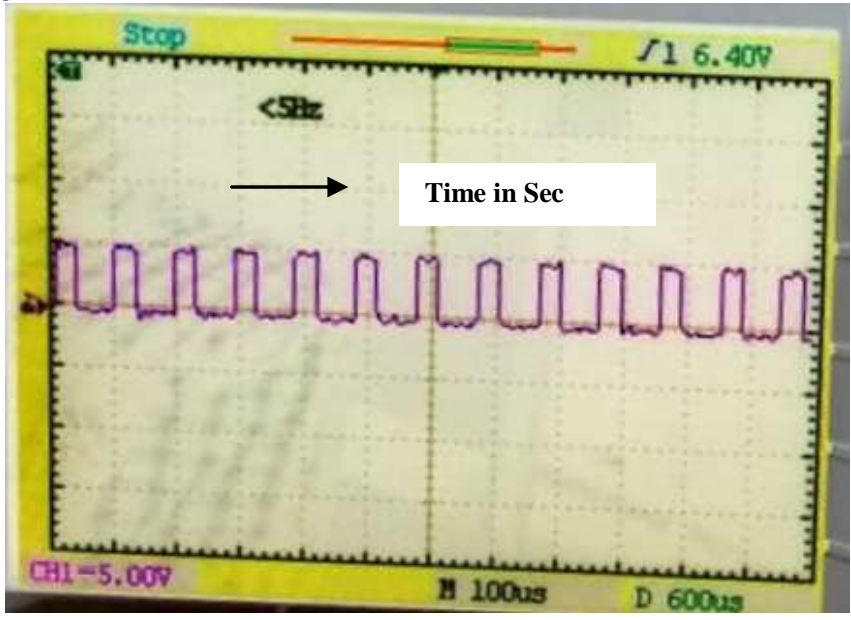

Figure 19 Switching pulse for SEPIC converter S1

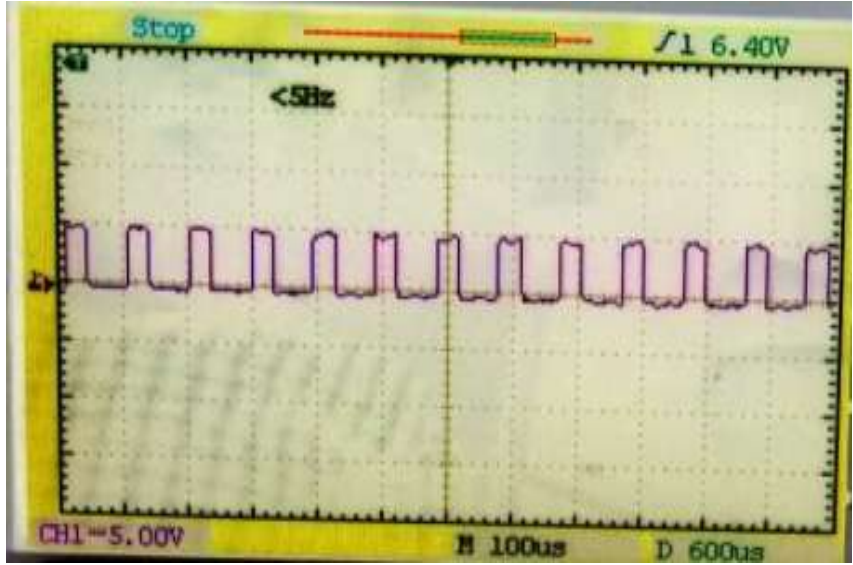

Figure 20 Switching pulse for SEPIC converter S2

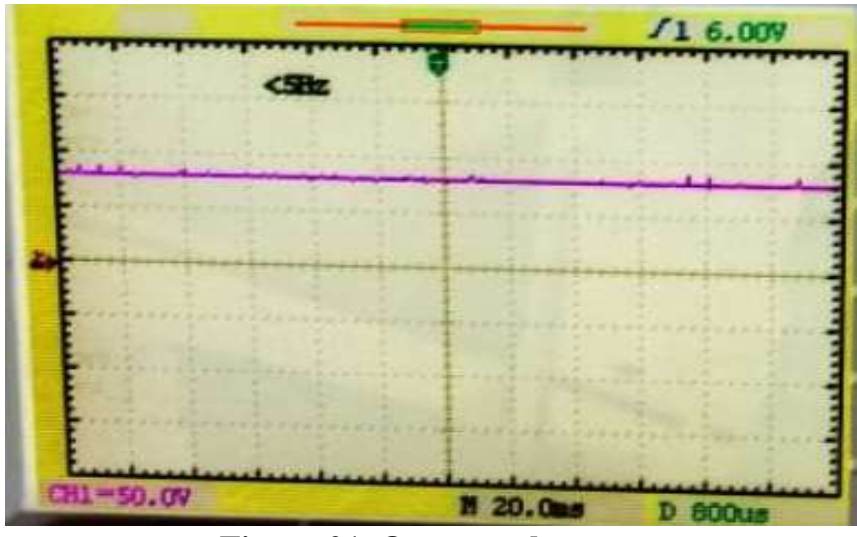

Figure 21. Output voltage

Hardware Diagram of Interleaved SEPIC Converter is delineated in Figure 22.

Published By:

Blue Eyes Intelligence Engineering \& Sciences Publication 


\section{FUZZY LOGIC CONTROLLED RENEWABLE ENERGY BASED DC SMART-GRID-SYSTEM WITH IMPROVED-PERFORMANCE}

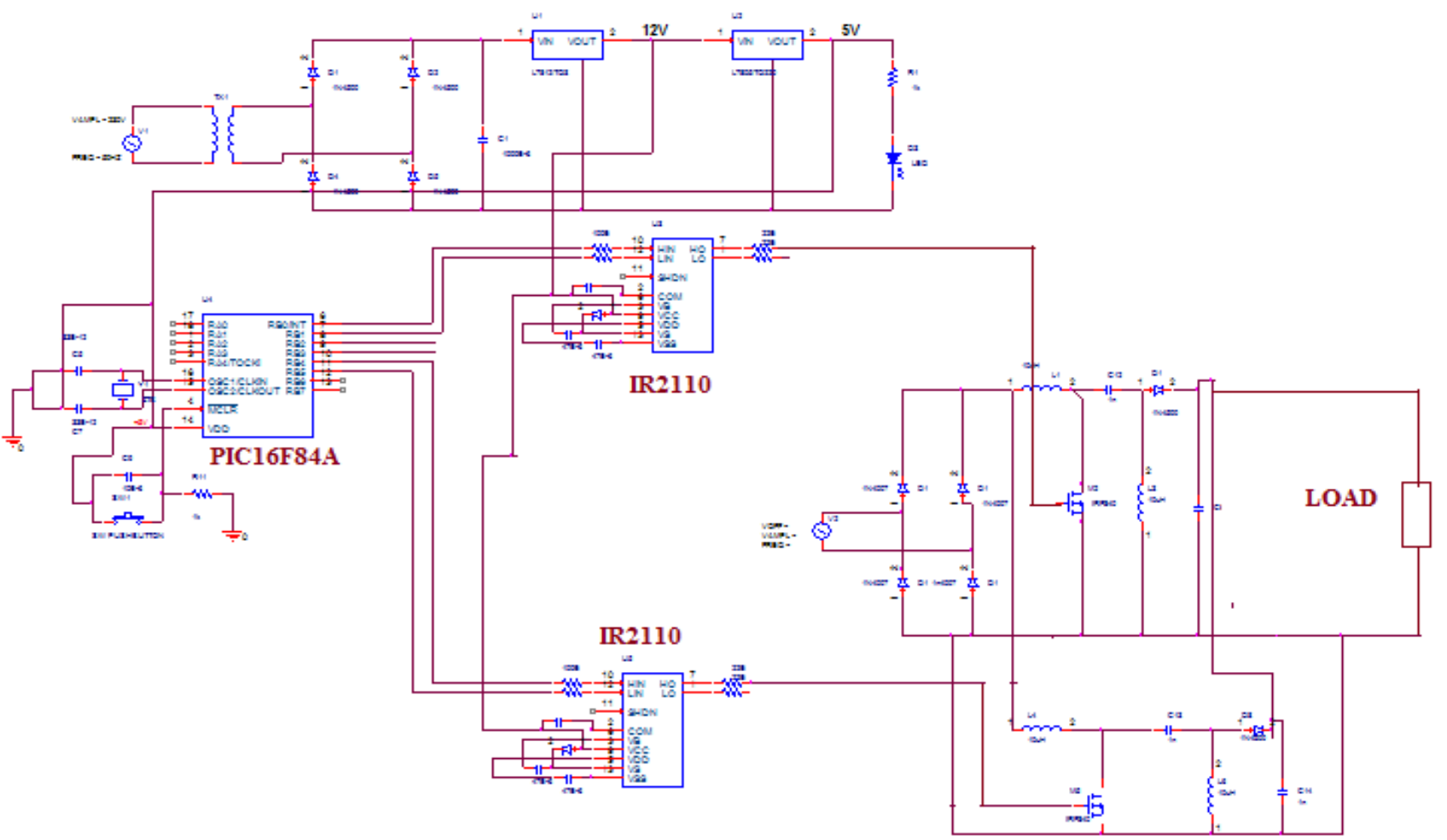

Figure 22 Hardware Diagram of Interleaved SEPIC Converter

\section{CONCLUSION} DC-SGS with FLC in PV-are represented \&simulated using MATLAB-Simulink. The outcomes are evaluated in terms of ST(settling-time) \&SSE(steady-state-error). By suing FLC controller, the ST (Settling time) is lessened from 0.50 to $0.20 \mathrm{Sec} \& \mathrm{SSE}$ (steady state error) is lessened from 2.8 to 0.7 Volts. Active-response is also enhanced by using FLC. Hence"-closed-loop-SEPIC-converter with FLC" is better than that of "the-closed-loop-SEPIC-converter with PR controller".

The-present-work is to evaluate-closed-loop DC-SGS with PR-controller \&closed-loop DC-SGS with FLC in PV. The comparison of closed loop DC smart grid system with FLC and SMC can be done in Future.

\section{REFERENCES}

1. F.Nejabatkhah,-Y.W.Li,

"-Overview-of-power-management--strategies-of-hybri d-

AC/DC-Microgrid", -IEEE-Trans.-P-E,-Vol-30,-no-12,pp-7072-7089, -2015.

2. -AbdallahL,-El-Shennawy.T."--Reducing-carbon-dioxide -emissions-from-electricity

sector-using-smart-electric-grid-applications". $\quad$-J-Eng. $-2013:-1-8$

3. -HossainMS, -Madlool NA, -Rahim NA, -Selvaraj J, -PandeyAK, -KhanAF. "-Role-ofsmart-grid-in-renewable-energy: -an-overview". -renew-sustain-energy-rev-2016; 60: -1168-84.

4. -KadaliKS,-Rajaji

L.

"-Evaluation-of-energy-in-wind-turbine-system-using-pr obability-distribution".-indonesian-journal-electrical-engi neering-computer-science-. 2018; 9(2): 294-298.

5. -Blaabjerg F.

"-Future-on-power-electronics-for-wind-turbine-systems
Closed loop DC-SGS with PR-controller \&Closed-loop

".-IEEE J-Emerg sel -top-power-electron. -2013; 1(3)-139-152

6. -FathabadiH.

"-Novel-maximum-electrical\&-mechanical-power-tracki ng-controllers- for-wind-energyconversion-systems". -i-EEE-j emerg sel-top-power-electron. -2017; 5(4): -1739-1745.

7. -ChenF, -HuangfuY, -ZhuoS, -XuL, -ZhaoD. "-Analysis\&-control-of-a-high-voltageratio-and-low-stress-DC-DC-Converter-for-fuel-cell-appl ications".-2017-IEEEon-industrial-tech-(icit)-toronto- 2017: 42-47.

8. -YangY, -LuoX, -DaiC, -ChenW, -LiuZ, -LiQ. "-Dynamic-modeling-and-dynamic -responses-of-grid-connected-fuel-cell". J-hydrogen-energy.-2014;-39(26): -14296-14305.

9. -LiS,-Haskew-TA,-LiD, -HuF. “-Integrating-photovoltaic and-power-converter characteristics for energy-extraction study-of-solar PV-Systems".-renew-energy. 2011; 36(12): 3238-3245.

10. -Subiyanto,-Mohamed A,-Hannan M a "-Intelligent-photovoltaic-maximum-power-point-trackin g-controller-for-energy-enhancement-in-renewable-energ y-system".-j renew-energy-2013: 1-9.

11. -RazzakMA, -BhuiyanWT,-NatashaNI, -IslamAKMM "-Design-of-grid-connectedphotovoltaic-inverter-with-maximum-power-point-tracki ng-using-perturb\&-observe- technique". -Int J-power-electron-drive-syst. -2016; 7(4): -1212-1220.

12. -BlaschkeT,-BiberacherM, -GadochaS,-SchardingerI. '-Energy-landscapes':-meeting energy-demands-andhuman-aspirations-biomass and-bioenergy.-2013;-55: 3-16. 
13. -IsenE,

-Bakan-AF."-10kW-grid-connected-three-phase-invertersystem :-control -simulation-and-experimental-results".-2012- ${ }^{\text {rd }}$-IEEE-in ternational-symposium-on power-electronics-fordistributed generationsystems (pedg). -denmark.-2012: -836-840.

14. -PrabaharanN,-PalanisamyK.

"-Analysis\&-integration-of-multilevel-inverter -configuration-with-boost-converters-in-a-photovoltaic-s ystem".-energy-convers manag-2016; -128: 327-342.

15. -AlongeF, -Pucci $\mathrm{M}, \quad$-Rabbeni $\mathrm{R}, \quad$-Vitale $\mathrm{G}$. "-Dynamic-modelling-of-a-quadraticdc/dc-single-switch-boost-converter". -electr-power-syst-Res. -2017; 152: -130-139.

16. -SitbonM, -Schacham -S,Suntio -T,Kuperman "-A-improved-adaptive-input-voltage -control-of-a-solar-array-interfacing-current-mode-contr olled-boost-power-stage. -energy-convers-manag". 2015; 98: 369-375.

17. -AbusorrahA, -Al-HindawiMM, -Al-Turki -Y,Mandal $-K$, Giaouris $\quad-D$, Banerjee $\quad S$, et al. “-Stability-of-a-boost-converter-fed-from-photovoltaic-s ource". -sol-energy.-2013; 98(pc): -458-471.

18. -DuY,-LuDDC.

"-Battery-integrated-boost-converter-utilizing-distributed -mppt- configuration-for-photovoltaic-systems". -sol-energy. -2011; 85(9): 1992-2002

19. -MarrekchiA, -KammounS,-SallemS,-Kammoun-MBA "-A-practical-technique-for -connecting-pvgenerator-to-single-phase -grid".- sol-energy- 2015; -118: $145-154$.

20. -MaksimovicD $-\mathrm{Cuk}$

"-Switching-converters-with-wide-dc-conversion-range". -ieee-trans-power-electron.-1991; 6(1): -151-157.

21. -Diaz-Saldierna -LH,-Morales-Saldaña-JA, Leyva-Ramos -J, Ortiz-LopezMG "-Switching - regulator-using-a-quadratic-boost-converte r-for-wide-dc-conversion- ratios". -iet-power-electron.2009;- 2(5): 605-613.

22. -Al-Saffar MA, -Ismail EH. "-A-high-voltage-ratio and-low-stress-DC-DC-converterwith-diminished-input-current-ripple-for-fuel-cell-source .-renew-energy" -2015; 82: 35-43.

23. -Y.Xu, -W.Zhang, -G. Hug, -S. Kar, Z.Li, "-Cooperative-control-of-distributed-energystorage-systems-in a-microgrid,"- ieee-trans.-smart-grid, -vol-6, no-1, pp-238-248, janu-2015.

24. -A.I. Dounis, -P.Kofinas, -G.Papadakis, ,-C.Alafodimos "-A-direct-adaptive-neura-1 control-for-maximum-power-point-tracking-of-photovolt aic-system," -Solar-Energy, vol- 115, pp-145-165, -2015.

25. -K.Rouzbehi, -A. Miranian, -J.I.Candela, -A. Luna,-P.Rodriguez,

"-A-generalized-voltage-droop-strategy-for-control-of-m ultiterminal-DC-Grids", -IEEE-Trans.-Ind.-Appl., -vol-51, -no-1,- pp-607-618, Jan./Feb- 2015.

26. -C.Wang, -X. Li, -L.Guo, -Y.Li, "-A-nonlinear-disturbance-observer-based-DC-Busvoltage-control -for -hybrid-AC/DC-microgrid", -IEEE-Trans.-Power-Electr on.,-vol-29, no- 11, pp-6162-6167, Nov-2014.

27. -B.Hu, -K.Xie, -H.Yang, -Z.Jiang, "-Evaluation-model-and-algorithm-for-wind-farm -capacity-credit-considering-effect-of-storage-system-usi ng-the-bisection-method", -Proc-IEEE-PES-Gen-Meetin g-Conf--Expo.,-pp- 1-6, -2014. 